\title{
El desarrollo de los derechos a la verdad, la justicia y la reparación en el Sistema Interamericano de Derechos Humanos y su influencia en el ordenamiento jurídico colombiano*
}

The development of the rights to truth, justice and reparation in the InterAmerican Human Rights System and its influence in the Colombian legal system

Yully Alexandra Sánchez Parra**

Carlos Eduardo Saraza Gómez**

Fecha de recepción: 15 de febrero de 2018

Fecha de aprobación: 10 de abril de 2018

\section{RESUMEN}

El presente artículo es el resultado de una revisión instrumental y jurisprudencial sobre la evolución que han tenido los derechos a la verdad, la justicia y la reparación en el Sistema Interamericano de Derechos Humanos; y de cómo, desde el constructo teórico que presuponen dichos instrumentos, se ha permeado el ordenamiento jurídico colombiano de manera tangible, hasta el punto de incluir tales preceptos normativos (derechos) como postulados

* Artículo presentado como resultado del proyecto de investigación realizado en el marco de la Especialización en Derechos Humanos de la Facultad de Ciencias Jurídicas, Sociales y Humanísticas, Fundación Universitaria del Área Andina, Seccional Pereira, Colombia. DOI: http://dx.doi.org/10.15332/s1909-0528.2018.0002.04

** Psicóloga, abogada, especialista en Derecho Administrativo y Constitucional, especialista en Derechos Humanos, maestranda en Psicología Jurídica y Forense, docente universitaria, Fundación Universitaria del Área Andina, Seccional Pereira, Colombia. Correo electrónico: asanchezp@areandina.edu.co

*** Abogado, especialista en Derechos Humanos, maestrando en Derecho, docente universitario, director del Semillero de Investigación en Derecho Procesal de la Fundación Universitaria del Área Andina, Seccional Pereira, Colombia. Correo electrónico: cesaraza@areandina.edu.co 
positivados en diferentes leyes internas. Esta actitud del legislador colombiano demuestra la fuerte influencia que representan los documentos y decisiones producidos por el sistema regional de protección de los derechos humanos en las decisiones, tanto políticas como jurídicas del país y, en últimas, un gesto incontrovertible referente al acatamiento de los estándares internacionales que el mismo sistema ha fijado en la materia.

Palabras clave: derechos humanos, justicia, reparación, Sistema Interamericano, verdad.

\section{Abstract}

This article is the result of an instrumental and jurisprudential review of the evolution of the rights to truth, justice and reparation in the Inter-American Human Rights System; and how, from the theoretical construct that these instruments presuppose, has permeated the Colombian legal system in a tangible way, to the point of including such normative precepts (rights) as positive postulates in different internal laws. This attitude of the Colombian legislator demonstrates the strong influence of the documents and decisions produced by the regional system of protection of human rights in the political and legal decisions of the country and, lastly, an incontrovertible gesture regarding compliance with international standards that the same system has fixed in the matter.

Keywords: human rights, Inter-American System, justice, reparation, truth.

\section{INTRODUCCIÓN}

Los derechos a la verdad, la justicia y la reparación que les asisten a las víctimas y que en la actualidad se pregonan ampliamente, no siempre tuvieron tal visibilidad en nuestro entorno. Estos encontraron su génesis en el derecho internacional humanitario $^{1}$ y en el derecho internacional de los derechos humanos ${ }^{2}$; donde paulatinamente fueron ganando terreno, extendiéndose progresivamente tanto en instrumentos de

1 También DIH.

2 También DIDH. 
sofw law, como en los pronunciamientos jurisdiccionales y consultivos producidos por el Sistema Interamericano de Derechos Humanos.

En un primer estadio, antes de que existiera el derecho a la verdad como tal, el Sistema Interamericano de Derechos Humanos (SIDH) veía su núcleo esencial como antítesis de la impunidad. Así, aquel fue evolucionando con las posturas jurisprudenciales y la producción de documentos especializados que se tradujeron en instrumentos de "derecho suave", útiles como criterios de interpretación tanto para la Comisión como para la Corte interamericanas.

Estos organismos lo veían como un derecho derivado de otras garantías contenidas expresamente en la Convención Americana de Derechos Humanos ${ }^{3}$; empero, a raíz de ese mismo desarrollo, llegó a convertirse en un derecho autónomo, aún sin encontrar norma positiva que lo contemplara expresamente.

Además de tal reconocimiento, se le dio un lugar materialmente inescindible al lado de los derechos a la justicia y la reparación, de tal suerte que se creó un estándar en el cual, para cumplir las obligaciones convencionales, se debe garantizar, por parte del Estado, el cumplimiento de la triada de derechos en conjunto.

La evolución de dicho estándar internacional ha irradiado los ordenamientos jurídicos de Latinoamérica y específicamente el colombiano, a tal punto, que su influencia ha llevado a que las normas internas positiven estos derechos, en cumplimiento de las obligaciones generales de garantía que se desprenden del artículo 2 de la $\mathrm{CADH}$.

De allí la importancia de este texto, pues permite destacar el proceso jurídico evolutivo que ha surtido el reconocimiento de los derechos a la verdad, la justicia y la reparación, no por una vía legislativa producto de las movilizaciones internas propias, sino como producto de las sentencias emanadas por la Corte Interamericana de Derechos Humanos, lo que invita a dar una mirada sobre la importancia que cobra este sistema y el impacto del mismo en el ordenamiento jurídico interno.

3 También CADH. 


\section{EVOLUCIÓN HISTÓRICA DE LOS DERECHOS A LA VERDAD, JUSTICIA Y REPARACIÓN EN EL SISTEMA INTERAMERICANO De Derechos Humanos}

En la segunda mitad del siglo pasado, la Organización de Estados Americanos (OEA) se dio a la tarea de instituir un régimen de defensa de los derechos humanos en el continente americano, labor esta que se vio cristalizada en el año 1979 cuando entró plena y efectivamente en vigor la disposición de la Convención Americana de Derechos Humanos, artículo $33 \mathrm{CADH}$, que organizó el sistema para la protección de tales derechos ${ }^{4}$.

Este sistema está conformado, por un lado, por todos los instrumentos internacionales que versan sobre el tema de derechos humanos y que han sido suscritos y ratificados por los Estados miembros; $y$, por el otro, por dos órganos encargados de velar por su observancia, cumplimiento y materialización: la Comisión Interamericana de Derechos Humanos — que ya existía desde el año 1959—y la Corte Interamericana de Derechos Humanos, los cuales, si bien cumplen funciones diferentes, pues el primero es de carácter cuasijurisdiccional y el segundo es de índole jurisdiccional, se hallan conectados teleológicamente en pro de la salvaguarda de los derechos superiores del hombres.

En razón al fin planteado con su creación, el SIDH ha desarrollado normas y pronunciamientos que tratan de ir siempre a la par con la evolución social, política, económica, y en últimas, con la mutación que tiene la aplicación de los derechos en los contextos y momentos históricos específicos ${ }^{6}$.

4 Sistema Interamericano de Protección de los Derechos Humanos. En adelante, el sistema o SIDH.

5 En concordancia con lo dispuesto anteriormente, es importante hacer referencia al análisis de la implementación del cosmopolitismo en América Latina, en razón a que "es una de las regiones del planeta donde existe más violencia, desigualdad y pobreza, aunado esto a la continua violación de derechos humanos, dejando ver que sí hay una comunidad que necesita de los beneficios que un Estado cosmopolita le podría brindar; es en este sentido, en que resulta procedente afirmar que la política social ha encontrado nuevos referentes dentro de la globalización, en la cual juega un papel central el esquema de necesidades humanas" (Llano, Rengifo y Rojas, 2018, p. 100).

$6 \mathrm{Al}$ respecto, es importante anotar que los sistemas de cooperación internacional, desde el escenario judicial, hoy representan un sistema de derecho penal internacional integral, que aún se encuentra en formación y que no reemplaza el sistema interno, sino lo complementa (Osorio, 2018). 
Ahora, si bien es cierto que no existe una clasificación que ordene o dé jerarquía a los derechos del ser humano, pues su propia naturaleza implica que todos ellos se encuentran en la misma esfera de lo fundamental, también lo es que existen algunos derechos que se "mueven" más, que se desarrollan y tienen una tendencia cambiante más dinámica que otros, obedeciendo precisamente a las variables sociales a las que anteriormente se hizo referencia.

En tal sentido, existe una tríada de derechos fundamentales de la que se evidencia una interesante evolución normativa y jurisprudencial en el ámbito de aplicación del SIDH y que ha despertado gran interés en la comunidad internacional, no solo por su alcance y dimensión en el mundo del derecho, sino también por las dinámicas propias de los conflictos armados internos y de las dictaduras del Cono Sur que permitieron poner el foco en el actuar de los Estados, en su responsabilidad internacional y, por ende, en la forma de resarcirla.

La propia Comisión Interamericana de Derechos Humanos ha reconocido que la carencia de información verificable en el contexto de las problemáticas de ruptura democrática e institucional en el hemisferio sur, han dado lugar a que el derecho a la verdad se convierta en la forma más plausible de réplica contra las graves violaciones a derechos humanos y que, aquel, aunado a la justicia y la reparación, se encumbre como la vía ideal para que los Estados desagravien a las víctimas. Así lo planteó el órgano del SIDH en el documento, Derecho a la verdad en las Américas (2014):

\footnotetext{
2. [...] la historia de los países del hemisferio se ha caracterizado por múltiples y reiteradas rupturas del orden democrático e institucional, situaciones de conflicto armado de carácter no internacional, guerras civiles y situaciones de violencia generalizada que se desarrollaron por largos períodos de tiempo, y que en algunos casos, todavía continúan vigentes. En esas circunstancias, ha sido frecuente la violación masiva y sistemática de derechos humanos y la comisión de graves infracciones al derecho internacional humanitario (en adelante "DIH") por parte de agentes estatales, particulares que operaron con apoyo, tolerancia o aquiescencia del Estado, y miembros de grupos armados ilegales.
}

3. La falta de información completa, objetiva y veraz sobre lo sucedido durante esos períodos ha sido una constante, una política de Estado e incluso una "estrategia de guerra”, como en el caso de la práctica de las desapariciones forzadas. Así, la Comisión 
ha señalado que "un difícil problema que han debido afrontar las recientes democracias es el de la investigación de las anteriores violaciones de derechos humanos y el de la eventual sanción a los responsables de tales violaciones".

4. El derecho a la verdad ha surgido como respuesta frente a la falta de esclarecimiento, investigación, juzgamiento y sanción de los casos de graves violaciones de derechos humanos e infracciones al DIH por parte de los Estados. Es a través de los esfuerzos para combatir la impunidad que los órganos del sistema han desarrollado estándares regionales que dan contenido al derecho a la verdad, y los Estados y la sociedad civil han desarrollado enfoques e iniciativas para implementarlos en una amplia gama de conceptos. Asimismo, el derecho a la verdad constituye uno de los pilares de los mecanismos de justicia transicional (p. 3).

Así, los derechos a la verdad, la justicia y la reparación ${ }^{7}$, han sido materia de grandes debates, análisis y posturas de parte de los Estados y de los órganos que conforman el sistema y cuya relevancia ha llevado, incluso, a formar de estos una unidad de derechos. Es decir, que se han dejado de considerar de manera aislada para darles una interpretación como bloque indiviso de derechos que crea efectos jurídicos y que resultan ser, recíprocamente, causa, consecuencia y fin de sí mismos.

Estos derechos se encuentran consagrados ya sea expresamente o por interpretación sistemática de las normas de los instrumentos internacionales que hacen parte del SIDH y de los demás documentos que los nutren. Es así como podemos hallarlos presentes, entre otras muchas reglas, en el artículo 8 de la Declaración de los Derechos de Hombre; en el artículo 18 de la Declaración Americana de los Derechos y Deberes del Hombre; en los artículos 8 y 11 de los Principios Fundamentales de Justicia para las Víctimas de Delitos y Abuso del Poder; en los artículos 2, 9, 10, 14 y 15 del Pacto Internacional de Derechos Civiles y Políticos; en los artículos 2, 3, 4 y 27 de los "principios de Joinet", en la Resolución 640/147 de Naciones Unidas; y

7 Valga anunciar desde ya que la "garantía de no repetición" se tiene prevista, para efectos de esta investigación, como una categoría que hace parte del derecho a la reparación integral. Por lo tanto, no se analizará como un derecho autónomo.

8 Este documento hace parte de los instrumentos de soft law que, si bien no son vinculantes, tienen especial relevancia como fuente interpretativa tanto para la CIDH como para la Corte IDH. 
por supuesto en la Convención Americana de Derechos Humanos, en sus artículos $1,8,25$ y 63 .

Lo anterior presupone una tarea evolutiva, jurídicamente hablando, pues en principio se contemplaban estos derechos, y principalmente el derecho a la verdad, como categorías abstractas sin un contenido jurídico definido y, por ende, sin núcleos esenciales diferenciales que pudieran hacerlas justiciables. Se definían incluso como derechos derivados de otros, dependientes; pero con el devenir de los tiempos y el discurrir sociojurídico, se les fue dando la relevancia jurídica y social de que se encuentran revestidos en la actualidad como instrumentos inequívocos para la protección de las víctimas en todos los escenarios.

Para lograr este perfeccionamiento, se tuvo que acudir a diversos mecanismos y organismos internacionales ${ }^{9}$, los cuales produjeron decisiones u opiniones que llevaron a dicha transformación, tal como se verá a continuación.

\section{INFORMES, INSTRUMENTOS DE SOFT LAW Y JURISPRUDENCIA del Sistema Interamericano de Derechos Humanos SOBRE LOS DERECHOS A LA VERDAD, JUSTICIA Y REPARACIÓN}

El derecho a la verdad tiene su génesis en el derecho internacional humanitario, perspectiva desde la cual inició su desarrollo. De tal suerte, que ya desde el año 1978 el Grupo de Trabajo sobre las Desapariciones Forzadas o Involuntarias de Naciones Unidas, había concluido sobre su estatus de derecho autónomo, pero fue posteriormente que se consagró de manera expresa en el proyecto denominado "Conjunto de principios para la protección y la promoción de los derechos humanos mediante la lucha contra la impunidad", también conocido como "principios de Joinet".

9 Es importante resaltar, de conformidad con Sánchez (2018), que: "la tensión entre neoliberalismo y derechos humanos en América Latina ha generado toda una literatura en la región que ha posibilitado el surgimiento de nuevos marcos analíticos en el derecho, como el neoconstitucionalismo, la incorporación en el derecho constitucional de conceptos como el 'buen vivir', o el surgimiento de nuevos conceptos como el de Estado constitucional regulador. Este último surge en un contexto de desarrollo económico volcado en la producción de materias primas y la consolidación constitucional de un discurso de los derechos; en dicho contexto las cortes constitucionales han asumido un importante protagonismo" (p. 95).

VIeI / Vol. 13, n. ${ }^{\circ} 2$ / Julio-diciembre 2018 / Bogotá D. C., Colombia / Universidad Santo Tomás / Pp. 107-127 
En el estudio que dio como resultado este importante instrumento, el jurista Louis Joinet advirtió que el derecho a la verdad o "el derecho a saber", como también lo llama, existe per se y tiene su origen en la lucha contra la impunidad, pero no deviene solo, sino que es necesaria su coexistencia con los derechos a la justicia y a la reparación para encontrar su satisfacción. Al respecto, dijo:

La lucha contra la impunidad tiene su origen en la necesidad de que se haga justicia, pero no puede centrarse únicamente en ese objetivo: castigar a los culpables. Debe responder a tres imperativos: sancionar a los responsables, pero también satisfacer el derecho de las víctimas a saber y obtener reparación y, además, permitir que las autoridades desempeñen su mandato como poder público que garantiza el orden público (1985, p. 27).

Y esta visión de cohesión o encadenamiento de la tríada de derechos planteada por Joinet, ha sido intensamente desplegada no solo en el SIDH por intermedio de todos sus actores, sino, incluso, en el Sistema Universal de Protección de Derechos Humanos.

Así, instancias como la Alta Comisionada de la ONU para los Derechos Humanos y la Secretaría General de las Naciones Unidas, han apoyado con ahínco la labor de desarrollo de estos derechos en el ámbito internacional; la primera ha reconocido expresamente su importancia para las naciones ${ }^{10}$ en el marco de conflictos como los de Sierra Leona y Timor Oriental y se ha encargado de la sistematización de la jurisprudencia y la doctrina internacionales sobre el derecho a la verdad, entre muchas otras labores destacables; la segunda, además de reconocer su existencia de manera expresa, ha tenido intervenciones cruciales para la historia en general y para el contexto colombiano en particular, como la que hizo en el marco del inicio de las conversaciones de paz entre el Gobierno nacional y los grupos paramilitares que aparece en el comunicado de prensa SG/SM/9400 de 1 de julio de 2004, en la que expresó: "se debe respetar plenamente el derecho a la verdad, a la justicia y a las reparaciones de las víctimas”.

10 "[...] el derecho de las naciones a conocer la verdad sobre hechos del pasado. Para evitar que las violaciones se repitan, el ejercicio íntegro y efectivo del derecho a la verdad es esencial". 
En este mismo sentido, el Relator Especial de Naciones Unidas Leandro Despouy sobre la independencia de los magistrados y abogados (2006), en su informe sobre la misión que le encomendaron realizar en Perú, resaltó en ese mismo año, en los términos vistos a continuación, que tanto la justicia como la reparación juegan un rol determinante para concretar o hacer efectivo el derecho a la verdad:

En la concreción del derecho a la verdad, el derecho a la justicia ocupa un lugar preeminente, puesto que garantiza el conocimiento de lo acontecido a través de la acción del poder judicial, que tiene a su cargo la investigación, la valoración de elementos de prueba y el enjuiciamiento de los responsables.

A su vez, el derecho a la justicia implica el derecho a un recurso efectivo, lo que se traduce en la posibilidad de hacer valer los derechos ante un tribunal imparcial, independiente y establecido por ley, asegurando al mismo tiempo que los culpables sean enjuiciados y castigados en el marco de un proceso justo, y culmine con una adecuada reparación a las víctimas. Así, desde el punto de vista del derecho a la justicia, la verdad es a la vez un requisito para determinar responsabilidades y el primer paso del proceso de reparación. La instancia judicial, debidamente substanciada, es el medio para alcanzar los altos valores de la verdad y la justicia. En esta perspectiva, la administración de justicia con independencia e imparcialidad constituye un instrumento de gran importancia para satisfacer el derecho a la verdad (párr. 17).

Por su parte, los órganos del SIDH han aportado con su actuar, para el crecimiento o ampliación de la visión y del alcance que deben tener estos derechos superiores.

La Comisión inició su intervención en tal sentido desde la década del setenta, cuando se hallaban en "auge" las investigaciones sobre las dictaduras de América del Sur. A partir de esa década y en las siguientes, inició una serie de "denuncias" y manifestaciones elevadas en los textos de sus informes, en las cuales hacía especial hincapié en el derecho que les asistía a los familiares de las víctimas de los regímenes dictatoriales a conocer, a saber diáfanamente lo que sucedió con sus familiares desaparecidos, es decir, a obtener la verdad de los hechos, tal que el informe anual de la Comisión Interamericana de Derechos Humanos (1986) resalta: "Nada puede impedir a los familiares conocer lo que aconteció con sus seres más cercanos” (p. 205).

Posteriormente, amplió el concepto del derecho a la verdad y lo fundamentó en sólidas bases jurídicas como los derechos a la información, a las garantías judiciales, 
a la protección judicial, a la protección de la ley, entre otros y lo afincó en el derecho positivo encontrando que el mismo se deriva de los artículos 1, 8, 13 y 25 de la Convención Americana de Derechos Humanos, como se puede ver en el Informe No 136/99, del 22 de diciembre de 1999, caso Ignacio Ellacuría y otros vs. El Salvador:

El derecho a conocer la verdad con respecto a los hechos que dieron lugar a las graves violaciones de los derechos humanos que ocurrieron en El Salvador, así como el derecho a conocer la identidad de quienes participaron en ellos, constituye una obligación que el Estado debe satisfacer respecto de las familias de las víctimas y a la sociedad en general. Tales obligaciones surgen fundamentalmente de lo dispuesto en los artículos 1 (1), 8 (1), 25 y 13 de la Convención (párr. 221).

Pero la Comisión no solo se limitó a reconocer y reforzar el concepto del derecho a la verdad en lo que atañe a los intereses particulares de los casos en concreto. Al contrario, desde esa misma época y hasta la actualidad, ha sostenido que ese derecho es de interés general, pues no solamente le asiste a las víctimas directas o indirectas de violaciones a derechos humanos, sino que le es dable su reconocimiento a la sociedad en general teniendo en cuenta las bases del desarrollo de los sistemas democráticos.

La Comisión propiamente dicha, se pronunció a este respecto, en los siguientes términos:

El derecho a la verdad es un derecho de carácter colectivo que permite a la sociedad tener acceso a la información esencial para el desarrollo de los sistemas democráticos y a la vez un derecho particular para los familiares de las víctimas, que permite una forma de reparación (párr. 24).

Del mismo modo la Relatoría para la Libertad de Expresión, Derecho a la Verdad, que hace parte de la Comisión manifestó que:

La interpretación de este derecho ha evolucionado y actualmente se considera, por lo menos por parte de la Comisión, que el derecho a la verdad pertenece a las víctimas y sus familiares y también a la sociedad en general. Conforme a esta concepción, el derecho a la verdad se basa no solo en el artículo 25, sino también en los artículos 1 (1), 8 y 13 de la Convención (CIDH, 2016). 
Innumerables resultan los pronunciamientos que ha realizado la Comisión Interamericana de Derechos Humanos en lo atinente al derecho a la verdad que, como ya se dijo, comporta también los derechos a la justicia y reparación (que contienen en su núcleo, además, la garantía de no repetición), pues se supone que al tener un carácter público la información sobre hechos y circunstancias en que ocurrieron cuestionables sucesos en materia de derechos humanos, la tendencia social debe apuntar a que hechos similares no se vuelvan a presentar.

Por su parte, la Corte Interamericana de Derechos Humanos, cumpliendo su rol principal de órgano jurisdiccional en el SIDH, ha orientado sus pronunciamientos sobre el tema del reconocimiento del derecho a saber, incluso desde épocas en que no se calificaba aún este derecho de tal forma. Es decir, que el precepto superior de la verdad y los que consigo van de la mano, fueron materia de reconocimiento tácito en los primeros fallos de la Corte IDH y su evolución se ha verificado hasta la actualidad en la que expresamente se han designado, nominado y reconocido.

Esta evolución jurisprudencial tuvo un hito importantísimo para el SIDH, cual fue el fallo emitido en el año 1988 en el denominado caso Velásquez Rodríguez, en el cual la Corte declaró como responsable al Estado de Honduras por la desaparición de su ciudadano hondureño Ángel Manfredo Velásquez Rodríguez.

En el numeral 5 de la parte resolutiva del caso de referencia: Velásquez Rodríguez vs. Honduras, en Sentencia del 29 de julio del 1988, la Corte estimó que dicho Estado vulneró los derechos contenidos en los artículos 1 (1), 7, 4 y 5 de la Convención Americana de Derechos Humanos; pero lo relevante de ese fallo fue que, además de la declaratoria de responsabilidad, hubo un reconocimiento expreso del derecho de las víctimas indirectas (entiéndase familiares del desaparecido) a conocer lo sucedido con su pariente, y hubo una decisión manifiesta que impuso la obligación de pagar una indemnización compensatoria que fuera justa para los familiares del señor Velásquez. "5. Decide que Honduras está obligada a pagar una justa indemnización compensatoria a los familiares de la víctima” (núm. 5).

Tal como lo señala la Comisión Colombiana de Juristas, la Corte Interamericana continuó con esa línea en su jurisprudencia y sucesivamente reconoció el derecho a la verdad a favor de las víctimas de desaparición forzada amparándose en los derechos 
a la justicia y al recurso judicial efectivo (artículos 8 y $25 \mathrm{CADH}$, entre otros que se presentan a continuación: caso Godínez Cruz vs. Honduras, Sentencia del 20 de enero de 1989, Serie C No 5, párr. 191; caso Castillo Páez vs. Perú, Sentencia del 3 de noviembre de 1997, Serie C No 34, párr. 90; caso Blake vs. Guatemala, Sentencia del 24 de enero de 1998, Serie C No 36, párr. 97; y caso Bámaca Velásquez vs. Guatemala, Sentencia del 25 de noviembre de 2000, Serie C No 70, párr. 201), pero a la par empezó a extender tal reconocimiento a todos los casos en los que se presentan graves violaciones a los derechos humanos. En tal sentido, hizo pronunciamientos en casos presentados contra países como Perú y Guatemala, como en el caso Barrios Altos vs. Perú, Sentencia de 14 de marzo de 2001, Serie C No 75 en los que diáfanamente reconoce el derecho a la verdad, así:

El derecho a la verdad se encuentra subsumido en el derecho de la víctima o sus familiares a obtener de los órganos competentes del Estado el esclarecimiento de los hechos violatorios y las responsabilidades correspondientes, a través de la investigación y el juzgamiento que previenen los artículos 8 y 25 de la Convención.

Y en el caso Myrna Mack Chang vs. Guatemala, Sentencia del 25 de noviembre de 2003, Serie C No 101:

[...] toda persona, incluyendo a los familiares de víctimas de graves violaciones de derechos humanos, tiene el derecho a la verdad. En consecuencia, los familiares de las víctimas y la sociedad como un todo deben ser informados de todo lo sucedido con relación a dichas violaciones.

Además del reconocimiento como derecho, la Corte ha sido enfática en recordar que la verdad tiene a su vez un carácter de obligatoriedad para los Estados, carácter que tiene asidero en las normas del derecho internacional de los derechos humanos, es decir, tanto en las normas convencionales como en las normas imperativas (ius cogen) que hacen parte del derecho internacional público, por lo que aquellos deben investigar y agotar todos los recursos disponibles en pro del conocimiento de la verdad de los hechos. Ha dicho la Corte al respecto de los siguientes casos:

Caso Masacre de Pueblo Bello vs. Colombia, Sentencia del 31 de enero de 2006, Serie C No 140: 
Las investigaciones y procesos abiertos por los hechos de este caso corresponden al Estado, deben ser realizados por todos los medios legales disponibles y culminar o estar orientados a la determinación de toda la verdad y la persecución y, en su caso, captura, enjuiciamiento y castigo de todos los responsables intelectuales y materiales de los hechos.

Caso Gelman vs. Uruguay, Sentencia del 24 de febrero de 2011, Serie C No 221

La satisfacción de la dimensión colectiva del derecho a la verdad exige la determinación procesal de la más completa verdad histórica posible, lo cual incluye la determinación judicial de los patrones de actuación conjunta y de todas las personas que de diversas formas participaron en dichas violaciones y sus correspondientes responsabilidades.

Estos reconocimientos expresos, tanto de parte de la CIDH como de la Corte IDH, han sido materia de análisis por parte de los órganos legislativos en América Latina, pero, especialmente, por parte del legislador colombiano que ha entendido la carga de obligatoriedad que implica para el Estado el cumplimiento de los estándares internacionales allí fijados y que presuponen el surgimiento de responsabilidad internacional en caso de incumplimiento.

Es por ello, que se dará un vistazo a la forma en que han influido tales pronunciamientos de manera directa en la producción normativa en Colombia.

\section{INFLUENCIA DEL SIDH ${ }^{11}$ EN LA PRODUCCIÓN DE NORMAS POR PARTE DEL LEGISLADOR COLOMBIANO}

Colombia, al ratificar el pacto de San José de Costa Rica mediante la Ley 16 de 1972, cedió parte de su soberanía y, de contera, parte de su libertad legislativa, pues se obligó a buscar la concordancia de la normativa interna con la internacional. Esto conforme a los mandatos que se desprenden de los artículos 1 y 2 de la Convención, que indican como deber de los Estados, la protección y garantía de los derechos

11 En el marco del Sistema Interamericano de Derechos Humanos, "los órganos del Sistema Interamericano de Derechos Humanos (SIDH), a través de los instrumentos mediante los cuales actúa, se han encargado de darle contenido a cada uno de los derechos reconocidos en la Convención americana” (Pérez, Cardona y Martínez, 2017, p. 67). 
humanos ${ }^{12}$ sin distinción alguna y la adopción de las medidas legislativas y de cualquier otro carácter para efectivizar tales derechos ${ }^{13}$.

En ejercicio de ese deber internacional, el Estado colombiano ha venido no solo ratificando más instrumentos internacionales que progresivamente protegen los derechos humanos, sino que también ha implementado legislación interna para cumplir ese cometido.

Teniendo en cuenta que el SIDH, por su naturaleza, emite pronunciamientos en clave de derechos humanos y ello implica una dosis de obligatoriedad para los Estados miembros, los pronunciamientos sobre la verdad, la justicia y la reparación toman esta característica.

Así, las disposiciones contenidas en las decisiones emitidas por la Comisión o por la Corte IDH se convierten en imperativos para que los Estados procedan a proveer a las víctimas el respeto y la garantía de tales derechos, lo cual se convierte, a su vez, en estándares internacionales que deben observar los Estados para el cumplimiento de sus obligaciones internacionales.

En el año 1986, por ejemplo, la Ley 70 aprobó la Convención contra la Tortura y otros Tratos o Penas Crueles, Inhumanas o Degradantes, adoptada por la Naciones Unidas el 10 de diciembre de 1984. Colombia se acogió a este instrumento, lo que implicó la observancia de la implementación no solo del articulado de la norma, sino, además, la promoción de todas las condiciones reales que permitieran su puesta en marcha.

12 De conformidad con Sánchez y Calderón (2017): "Al ser concebidos como universales, los derechos humanos no deberían tener fronteras ni nacionalidad, puesto que están dirigidos a todos los seres humanos. Al ser universales, trascienden las fronteras y al dirigirse hacia la protección de los individuos, se deben dejar a un lado las ciudadanías y/o nacionalidades. Por lo tanto, son los Estados los que tienen la obligación de garantizar a cualquier individuo su cumplimiento, sin importar si es o no nacional del Estado en que se encuentre" (p. 55).

13 En concordancia con lo dispuesto, es importante resaltar que a la fecha se evidencia inseguridad jurídica por la restricción del control de constitucionalidad frente a los actos legislativos que fueron expedidos dentro del procedimiento especial para la paz, "el cual se ha denominado fast track, ya que este se limita a que su control se realice solamente por vicios en la formación del procedimiento, negando la posibilidad que el ciudadano ejerza la acción pública de inconstitucionalidad frente al surgimiento de dichos actos; por tanto, se hace notoria la vulneración del poder constituyente primario, ya que no se ejecuta un control amplio de estos actos, los cuales en muchos casos no se encuentran exentos de vicios en su contenido o en esencia” (Joya y Sánchez, 2018, p. 202). 
En la actualidad, esta "cesión de soberanía legislativa" tiene sustento constitucional en los artículos 93 y 94 constitucionales, los cuales promueven la relación normativa nacional e internacional y la prevalencia de los tratados sobre derechos humanos en el orden interno.

En uso de dicha cláusula, se han aprobado numerosas leyes internas tendientes a la observancia de los estándares internacionales sobre verdad, justicia y reparación:

La Ley 288 del 5 de julio de 1996, establece una relación directa entre la normativa interna y los órganos internacionales de protección de los derechos humanos. Esta ley estableció instrumentos para la indemnización de perjuicios a las víctimas de violaciones de derechos humanos en virtud de lo dispuesto por determinados órganos internacionales de derechos humanos, entre ellos, la Comisión IDH.

En desarrollo de esta ley, se implementó el Decreto 1818 de 1998, el cual, en su título XIII, previó como mecanismo alternativo de solución de conflictos, la "conciliación para la indemnización de perjuicios causados a víctimas de la violación a los derechos humanos, en virtud de decisiones de organismos internacionales de defensa de los derechos humanos".

Posteriormente, el Estado colombiano promulgó la Ley 975 de 2005, conocida como la "Ley de Justicia y Paz", la cual fue objeto de control constitucional mediante Sentencia C-370 de 2006. En esta norma, se acogen de manera directa las indicaciones de estándares internacionales fijados por la Corte IDH en lo referente a verdad, justicia y reparación.

Ello se logra evidenciar desde la parte teleológica de la misma, en donde se reconoce como uno de los objetos principales, la garantía de los derechos de las víctimas a la verdad, la justicia y la reparación. Además de ello, en su artículo 2 la norma entiende que su interpretación estará basada en la Constitución Política y en los tratados internacionales ratificados por Colombia. Esta última consideración implica, entonces, que se debe atender a las decisiones de la CIDH y de la Corte IDH como órganos encargados de la verificación de los deberes internacionales de los Estados miembros del Pacto de San José. 
Podría considerarse que esta disposición legal obedeció de alguna manera a las decisiones coetáneas emitidas por la Corte IDH como la del caso de la señora Myrna Mack Chang, antes referenciada, en la cual reiteró que el derecho a la verdad no solo se considera como un derecho de dimensiones individuales (víctima y familiares) y colectivo (sociedad en general), sino que, ejercido en una situación concreta, constituye también una forma de reparación.

Bajo el entendido de que los pronunciamientos de la Corte IDH tienen fuerza vinculante para los Estados parte de la convención, Colombia, con miras a la implementación de la "Ley de Justicia y Paz", quiso incluir las condiciones necesarias para la garantía de los derechos a la verdad y la justicia de las víctimas y así evitar posibles riesgos de responsabilidad internacional posterior.

Si lo logró o no, hace parte de un debate diferente, porque, por ejemplo, en la sentencia del año 2006 en el caso de la masacre de Pueblo Bello en la que la Corte IDH declaró internacionalmente responsable al Estado colombiano, se avizora dentro de las peticiones de la Comisión, que se ordenara al Estado adoptar medidas de reparación, entre ellas medidas para el esclarecimiento de la verdad como parte del proceso de reparación para las víctimas.

Lo que sí se devela como diáfano, es la intención del legislador colombiano de incluir los estándares internacionales, en la norma producida. Y también aparece claro el propósito de mantener estos estándares en las normas subsiguientes, no solo para cumplir con los deberes esenciales del Estado, sino en pro del principio de progresividad que se debe verificar en materia de derechos humanos.

Esto quiere decir que, si el legislador ya previó expresamente en normas anteriores los derechos a la verdad, la justicia y la reparación, no podría legislar regresivamente desconociéndolos en leyes posteriores.

La aplicación progresiva de tales derechos se ve reflejada en leyes como la Ley 1424 de $2010^{14}$, que tanto en su título como en la definición de su objeto anuncia la garantía y satisfacción de los derechos a la verdad, justicia y reparación a favor de las

14 Conocida como "Ley de Desmovilizados". 
víctimas de personas que se desmovilicen de grupos armados al margen de la ley. La previsión progresiva de esta ley se destaca en la contribución que deben hacer los desmovilizados a la reconstrucción de la verdad histórica del conflicto armado interno y a la reparación de las víctimas.

Un ańo después, nació a la vida jurídica la Ley 1448 de $2011^{15}$, en la que el legislador colombiano definió como objeto el establecimiento de un conjunto de medidas judiciales, administrativas, sociales y económicas por parte del Estado colombiano para posibilitar el goce efectivo de los derechos a la verdad, la justicia y la reparación, incluyendo dentro de esta última categoría, la garantía de no repetición, garantizando con ello, nuevamente el principio de progresividad normativa en materia de derechos humanos.

Como último en orden cronológico, pero tal vez más importante en cuanto a su relevancia normativa, el Congreso de la República de Colombia produjo el Acto Legislativo 01 de 2012 o "Marco Jurídico para la Paz". Este instrumento normativo de rango constitucional implica la preparación jurídica del Estado colombiano para asumir los retos que trae consigo la salida negociada del conflicto armado no internacional.

Y se menciona como el más relevante en términos jurídicos, porque a través suyo ${ }^{16}$, los derechos a la verdad, la justicia y la reparación (esta última incluye la garantía de no repetición), quedan elevados positivamente a rango constitucional. Es decir, con esta norma se decanta formalmente la prevalencia de los instrumentos internacionales en materia de derechos humanos en el orden interno. Puede aseverarse que es la materialización de la influencia directa de los pronunciamientos del SIDH en el ordenamiento jurídico interno, pues se trata de la inclusión directa de la línea jurisprudencial de la Corte IDH al contenido taxativo de la Carta Política.

En otras palabras, se comprueba la intención legislativa de incorporar positivamente y progresivamente al ordenamiento jurídico colombiano, los derechos a la verdad, la justicia y la reparación que, se itera, han sido producto de un constructo jurídico de

15 También conocida como "Ley de Víctimas y Restitución de Tierras".

16 Artículo 1, que introduce el artículo 66 transitorio a la Constitución nacional.

VIeI / Vol. 13, n. ${ }^{\circ} 2$ / Julio-diciembre 2018 / Bogotá D. C., Colombia / Universidad Santo Tomás / Pp. 107-127 
largos años y diversas posturas, pero gracias a la actividad conjunta (jurisprudencial/ legislativa), se han encumbrado hoy en lo más alto de la pirámide normativa del Estado colombiano: la Constitución Política de la República de Colombia ${ }^{17}$.

\section{Conclusiones}

Ríos de tinta se han vertido sobre el asunto y en países como Colombia, con el ordenamiento y el sistema jurídico existentes, aunados al conflicto armado no internacional que se vive, serán muchos más los que falten por verter.

Sin embargo, se puede resaltar que, los puntos realmente axiales en la discusión sobre los derechos a la verdad, la justicia y la reparación, son:

- Estos derechos han ido evolucionando en el SIDH al ritmo que exigen los cambios sociopolíticos presentados en el continente, más que nada por fuerza de las dictaduras y los conflictos armados no internacionales.

- Hoy más que nunca está absolutamente claro el reconocimiento de estos derechos no solo respecto del interés particular en un caso concreto, sino al que le asiste a la sociedad en general.

- Verdad, justicia y reparación conforman una tríada, un tríptico inescindible, pues forman parte de un mismo núcleo esencial. Esta forma de verlos, les brinda a las víctimas verdaderas garantías frente a las actuaciones de los Estados en el cumplimiento de sus deberes internacionales de protección y garantía.

- Los órganos integrantes del SIDH y las autoridades judiciales al interior de cada Estado han ido tomando consciencia en cuanto a la obligatoriedad del reconocimiento y cumplimiento de tales derechos, lo que se traduce en be-

17 En atención a lo dispuesto en el respectivo subtema, es importante resaltar que: "En el marco de la Carta Política colombiana de 1991, el cambio de Estado de derecho al modelo de Estado social de derecho permitió formas pluralistas democráticas incluyentes" (Palomares, 2017, p. 14), lo cual permite una mayor protección y garantía al cumplimiento de los derechos humanos. 
neficio para la sociedad que es uno de los fines últimos del derecho como disciplina transversal a todos los ámbitos de la vida humana.

- Parece emerger como indudable, al menos prima facie, que el ordenamiento jurídico interno en Colombia se ha visto permeado e influenciado en gran medida por las visiones, el desarrollo y los estándares internacionales que se han fijado respecto de los derechos comentados en este texto, hasta el punto de tenerlos como derechos positivos en varias normas producidas por el legislador y como puntos de referencia para los pronunciamientos judiciales en favor de las víctimas.

\section{REFERENCIAS}

Cancillería. (2013). Cancillería Corte interamericana de Derechos Humanos. Recuperado de www.cancilleria.gov.co/sites/files/Litigio\%20Nicaragua-Col/Sentencia_caso_12.1573_ lopez_y_otros_28operacion_genesis29.pdf

Caso Barrios Altos vs. Perú. (14 de marzo de 2001). Corte Interamericana de Derechos Humanos.

Caso Gelman vs. Uruguay. (24 de febrero de 2011). Corte Interamericana de Derechos Humanos.

Caso Masacre Pueblo Bello vs. Colombia. (31 de enero de 2006). Corte Interamericana de Derechos Humanos.

Caso Myrna Mack Chang vs. Guatemala. (25 de noviembre de 2003). Corte Interamericana de Derechos Humanos.

Caso Velásquez Rodriguez vs. Honduras. (29 de julio de 1988). Corte Interamericana de Derechos Humanos.

Colectivo de abogados. (2015). Caso masacre de Mapiripán vs. Colombia. Recuperado de https://www.colectivodeabogados.org/spip.php?page=recherche\&recherche=caso + mapi ripan+vs.+colombia 
Comisión Interamericana de Derechos Humanos. (Enero de 1989). Corte IDH. Recuperado de www.corteidh.or.cr/docs/casos/aticulos/series/sentenciac_05_esp.pdf

Comisión Interamericana de Derechos Humanos. (2014). Derecho a la verdad en las Américas. Washington: OEA.

Comisión Interamericana de Derechos Humanos. (23 de agosto de 2016). Relatoría para la Libertad de Expresión, Derecho a la verdad. Recuperado de http://www.cidh.org/relatoria/showarticle.asp?artID=156\&lID=2.

Corte Interamericana de Derechos Humanos. (Mayo de 2004). Corte IDH. Recuperado de www.cidh.or.cr/docs/casos/articulos/seriec_106_pdf

Corte Interamericana de Derechos Humanos. (22 de noviembre de 2004). Corte IDH. Recuperado de www.corteidh.or.cr/docs/casos/articulos/sentenciac_esp.pdf

Corte Interamericana de Derechos Humanos. (22 de noviembre de 2016). Corte IDH. Recuperado de www.corteidh.or.cr/tablas/r28160.pdf

Despouy, L. (2006). Informe del Relator Especial sobre la independencia de los magistrados y abogados. Washington: Naciones Unidas.

Díaz , F. (2013). Conflicto, mediación y conciliación desde una mirada restaurativa y psicojurídica. Bogotá D. C., Colombia: Pontificia Universidad Javeriana-Grupo Editorial Ibañez.

Díaz, F. (2013). La justicia desde las víctimas. Bogotá D. C., Colombia: Pontificia Universidad Javeriana-Grupo Editorial Ibáńez.

Hernández, Sampieri , R. (2010). Metodología de la investigación (Vol. 5). Bogotá D. C., Colombia: McGraw Hill.

Joya, D., y Sánchez, A. (2018). Inseguridad jurídica ante el impedimento del ejercicio de la acción pública de inconstitucionalidad dentro del proceso especial para la paz. Revista IUSTA, 1(48), 199-225. Recuperado de http://revistas.usta.edu.co/index.php/iusta/ article/view/4093/3887

Llano, J. V., Rengifo, R. A., y Rojas, L. M. (2018). Estado cosmopolita en América Latina. Revista IUSTA, 1(48), 97-117. DOI: https://doi.org/10.15332/s1900-0448.2018.0048.04. Recuperado de http://revistas.usta.edu.co/index.php/iusta/article/view/4088/3883 
OAS. (15 de septiembre de 2016). OAS More rights for more people. Recuperado de http:// www.oas.org/en/sla/esp/tratados_B32_Convencion_Americana_sobre_Derechos_Humanos.htm

Osorio, R. (2018). La extradición y la cooperación internacional. Falta de justicia, legitimidad o incapacidad del Estado colombiano: su historia. Revista IUSTA, 1(48), 179-198. DOI: https://doi.org/10.15332/s1900-0448.2018.0048.07. Recuperado de http://revistas.usta.edu.co/index.php/iusta/article/view/4097/3904

Palomares, J. (2017). El balanceo constitucional y la aplicación del método de proporcionalidad en las encuestas electorales. Revista Via Inveniendi et Iudicandi, 12(2), 11-51. DOI: http://dx.doi.org/10.15332/s1909-0528.2017.0002.01. Recuperado de http://revistas. usantotomas.edu.co/index.php/viei/article/view/3750/3712

Pérez, A., Cardona, A., y Martínez, V. (2017). Estándares interamericanos sobre la libertad de expresión respecto de funcionarios y candidatos a ocupar cargos públicos. Revista Via Inveniendi et Iudicandi, 12(1), 67-88. Recuperado de http://revistas.usantotomas.edu. co/index.php/viei/article/view/3562/3450

Sánchez, C., y Calderón, D. (2017). Geopolítica de los derechos humanos en las fronteras terrestres de Colombia en el primer período presidencial de Juan Manuel Santos. Revista Via Inveniendi et Iudicandi, 12(2), 53-72, DOI: http://dx.doi.org/10.15332/s19090528.2017.0002.02. Recuperado de http://revistas.usantotomas.edu.co/index.php/viei/ article/view/3752/3714

Sánchez, R. (2018). La regulación de participación. El caso de la consulta previa en Colombia, Perú y Chile. Revista Via Inveniendi et Iudicandi, 14(1), 95-118. DOI: http:// dx.doi.org/10.15332/s1909-0528.2018.0001.03. Recuperado de http://revistas.usantotomas.edu.co/index.php/viei/article/view/4267/4044 